\title{
Brake Compensation Control for In-wheel Motor Drive System Failure
}

\author{
Zhang Run Sheng ${ }^{1}$, Li Liang ${ }^{1}$, Zhang Si Long ${ }^{1}$, Zhang Wei ${ }^{1}$ and Zhang Li Peng ${ }^{1, a^{*}}$ \\ ${ }^{1}$ School of Vehicle and Energy, Yanshan University, Qinhuangdao, China \\ a evzlp@ysu.edu.cn \\ *corresponding author
}

Keywords: Electric Vehicle, In-wheel Motor Drive, Failure, Brake Compensation

\begin{abstract}
The in-wheel-motor drive electric vehicle has the advantages of compact structure, high efficiency and easy controllability. But once all of the unilateral drive systems are failure in the strong driving situation, the vehicle will be transient instability under the additional yaw moment produced by the torque of the normal driving wheels. To solve the above problem, the vehicle stability simulation analysis in the situations of unilateral drive system failure was carried out, the coupling relationship between the torque output from the drive systems and the vehicle stability was determined, and the dynamics mechanism of the vehicle transient instability was revealed. On the basis of the decoupling of the vehicle plane stability control parameters, an active yaw moment control strategy based on the electro-hydraulic composite braking compensation in the vehicle instability critical region was developed, and the simulation verification of the failure control was completed. The brake compensation control strategy is able to take the initiative to coordinate the torque coupling characteristics between the in-wheel motors and the hydraulic braking system, which ensures the vehicle stability after the failure of unilateral drive systems.
\end{abstract}

\section{Introduction}

Each drive wheel of the in-wheel-motor drive electric vehicle has an individual drive system, compared with a single-motor centralized drive electric vehicle, which can simplify the transmission link, reduce the difficulty of overall layout and improve the driving efficiency [1]. The rotational speed and the driving torque of each drive wheel can be adjusted individually to facilitate the achievement of a variety of active safety controls [2,3]. Therefore, the use of the in-wheel motor drive systems has become an important research direction of the development of high performance electric vehicles.

However, the in-wheel motor drive electric vehicle is a relatively immature system with multiple components and complicated control technology. Coupled with the operation of changeable environment, many kinds of failure phenomenon may be appearing in the drive system. The electrical components will be damaged by the poor external conditions and improper use. Because 
the locations of the drive systems are different, the phenomenon of unilateral drive systems failure will appear [4].

Due to the cancelling of a differential, the driving torque cannot be automatically distributed between the coaxial drive wheels of an in-wheel motor drive electric vehicle. The driving torque act on each wheel is entirely determined by the corresponding drive system. Therefore, once the unilateral drive system failure is happen in the strong driving situation of a two-wheel independent drive electric vehicle as shown in figure 1, the additional yaw moment generated by the longitudinal force of the normal driving wheel will form a steering disturbance, which may cause the vehicle transient instability [5]. In theory, once the failure of the left front wheel drive system has been detected, the driving torque of the right front wheel drive system might be simultaneously reduced to zero within a few milliseconds to make the vehicle stably decelerate, but it is just an ideal situation. In fact, the instability swerving may be still occurring in some conditions. There are two reasons: on one hand, some types of the drive system failures such as the mechanical parts damage cannot be directly reflected by the feedback signals, the time occupied by the indirect detection of these failures may exceed tens of milliseconds, and the control system response also take some time, so the driving torque output from the normal working drive system is much larger than that of the failure drive system for a moment; on the other hand, the subsequent impact of the load transient transfer caused by the plummeted driving torque will play a role in the intensification of the vehicle bending.

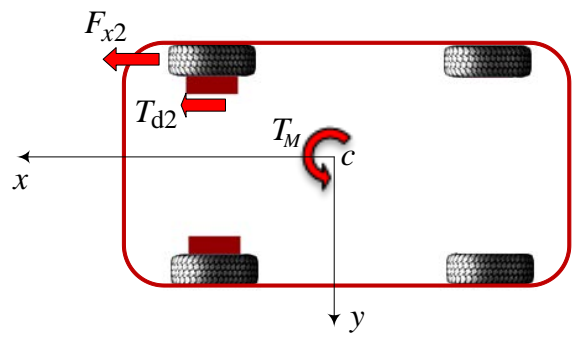

Figure 1 Dynamics analysis

Although some research on the stability control of the electric vehicles with in-wheel motor drive systems failure have been done, most of them are about the failure of a single drive system or two drive systems at the different sides of a four-wheel drive vehicle [6], and lack of the specific studies on the unilateral drive systems failure. Reference [7] adjusts the normal drive motors' torque to zero when the unilateral drive systems are fault, but the response delay was not considered. In reference [8], the brake compensation control is realized by using the braking torque of the normal working drive system to improve the vehicle stability, but the compensation torque at high speed is not enough to timely correct the vehicle movement.

To resolve the instability problem caused by the unilateral drive system failure of a two-motor front wheels drive electric vehicle, the paper attempts to use the braking torque of the hydraulic braking system to compensate the regulation torque of the normal working motor. And based on the vehicle instability mechanism analysis, the corresponding control strategy is researched $[9,10]$. The paper is organized as follows. Section 2 presents the dynamics model and the system parameters. Section 3 reveals the dynamics mechanism of the vehicle transient instability caused by the unilateral drive system failure; Section 4 develops an active yaw moment control strategy based on the electro-hydraulic composite braking in vehicle instability critical region; Section 5 completes the simulation verify of the failure control in emergency accelerating condition. Finally, some conclusions are gathered in Section 6 . 


\section{Dynamic model and parameters}

\subsection{Drive system model}

The driving torque output from the drive system can be expressed as [11]:

$$
T_{d i}=\eta_{\mathrm{T}} \kappa\left(\frac{T_{m i}^{*}}{1+2 \xi s+2 \xi^{2} s^{2}}-I_{m} \dot{\Omega}_{i}-R_{\Omega} \Omega_{i}\right)
$$

where $\eta_{\mathrm{T}}$ is the system transmission efficiency, $\kappa$ is the reduction ratio, $T_{m i}^{*}$ is the internal rotor motors target torque, $\xi$ is the relative damping coefficient which can be obtained by the fitting of test results.

\subsection{Brake system model}

The active braking pressure control is achieved by hydraulic control unit. The model may be simplified by the first-order integration element. Considering the delay character of the hydraulic plump system, an inertial element is introduced in the model as shown in figure 2 , where $p_{b}$ is the target pressure value, $u$ is the pressure change rate, $u_{g}$ is the pressure growth rate, $u_{d}$ is the pressure reduction rate, $u_{0}$ is regarded as 0 which denotes the pressure is unchanged, and $\tau_{p}$ is the time lag coefficient. Finally, the target pressure calculated by the controller is changed to the pressure change rate. And the pressure adjustment is achieved though the change in the opening of the solenoid valves [12].

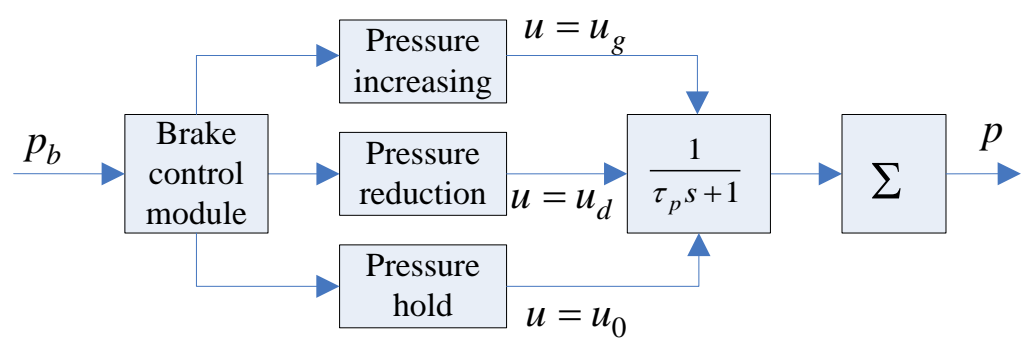

Figure 2 Braking pressure model

Hence, the real pressure in the wheel cylinders can be expressed as follows:

$$
p=\sum u \Delta T
$$

where $\Delta T$ is the control period in the discrete systems.

The relationship between the wheel cylinders pressure and braking torque can be defined as:

$$
T_{b}=2 r \mu_{b} p \pi D^{2} / 4
$$

where $D$ is the diameter of the wheel brake cylinders, $r$ is the brake disc radius, and $\mu_{b}$ is the brake disc friction coefficient. 


\subsection{Vehicle model}

The dynamics simplified model of a front wheels drive electric vehicle in linear acceleration can be expressed as:

$$
\begin{gathered}
m\left(\dot{v}_{x}-v_{y} \gamma\right)=F_{x 1}+F_{x 2}-C_{\mathrm{D}} A\left(3.6 v_{x}\right)^{2} / 21.15 \\
m\left(\dot{v}_{y}+v_{x} \gamma\right)=F_{y 1}+F_{y 2}+F_{y 3}+F_{y 4} \\
I_{z} \dot{\gamma}=\frac{B}{2}\left(F_{x 2}-F_{x 1}\right)+a\left(F_{y 1}+F_{y 2}\right)-b\left(F_{y 3}+F_{y 4}\right) \\
I_{\omega} \dot{\omega}_{i}=T_{d i}-r_{s}\left(F_{x i}+F_{z i} f\right)-T_{b i}
\end{gathered}
$$

where $v_{x}$ is the vehicle longitudinal velocity, $v_{y}$ is the vehicle lateral velocity, $\gamma$ is the yaw rate, $F_{x i}$ and $F_{y i}(\mathrm{i}=1,2,3,4)$ are the longitudinal force and lateral force, $\delta$ is the front wheels steering angle, $a$ and $b$ are the distance from front axle or rear axle to the centroid, $\mathrm{B}$ is the distance between the wheels at left side and right side, $C_{\mathrm{D}}$ is the air resistance coefficient, $A$ is the vehicle frontal area, $f$ is the rolling resistance coefficient, $\omega_{i}$ is the wheels angular speed, and $r_{s}$ is the wheel rolling radius.

The tire force is written as [13]:

$$
Y\left(x_{i}\right)=\mathrm{D} \sin \left\{\mathrm{C} \arctan \left[\mathrm{B} x_{i}-\mathrm{E}\left(\mathrm{B} x_{i}-\arctan \left(\mathrm{B} x_{i}\right)\right)\right]\right\}
$$

where $Y\left(x_{i}\right)$ is the longitudinal tire force or the lateral tire force; $x_{i}$ is the slip angle $\alpha_{i}$ or the slip ratio $\lambda_{i}$, which can be calculated according to the corresponding formula in reference [11]; the fitting coefficients B, C, D, and E depend on the wheel load $F_{z i}$ and the slip ratio $\lambda_{i}$ [14].

\subsection{Model parameters}

The model main parameters are given by Table 1 .

Table 1 Model parameters.

\begin{tabular}{|c|c|}
\hline Parameters & Value \\
\hline Vehicle mass $\lambda_{i}(\mathrm{~kg})$ & 1650 \\
\hline Wheels radius $r_{s}(\mathrm{~m})$ & 0.307 \\
\hline Wheels distance $B(\mathrm{~m})$ & 1.565 \\
\hline Distance from front axle to centroid a(mm) & 1.193 \\
\hline Distance from rear axle to centroid $\mathrm{b}(\mathrm{mm})$ & 1.597 \\
\hline Inertia moment of the vehicle $I_{z}(\mathrm{~kg} / \mathrm{m} 2)$ & 2280 \\
\hline Rolling resistance coefficient $f$ & 0.015 \\
\hline Frontal area $A(\mathrm{~m} 2)$ & 2.1 \\
\hline Air resistance coefficient $C_{\mathrm{D}}$ & 0.34 \\
\hline Wheel inertia $I_{\omega}(\mathrm{kgm} 2)$ & 1.7 \\
\hline Reduction ratio $\kappa$ & 7.03 \\
\hline
\end{tabular}




\begin{tabular}{|c|c|}
\hline Mechanical efficiency $\eta_{T}$ & 0.94 \\
\hline Motor fitting function $\xi$ & 0.0076 \\
\hline Motor inertia $I_{m}(\mathrm{kgm} 2)$ & 0.08 \\
\hline motor drag coefficient $R_{\Omega}$ & 0.02 \\
\hline Brake disc friction coefficient $\mu_{b}$ & 0.38 \\
\hline Front wheels brake disc radius $\mathrm{r}$ & 0.122 \\
\hline
\end{tabular}

The relationship between the tire force and the slip ratio under different road conditions is illustrated in Figure 3.

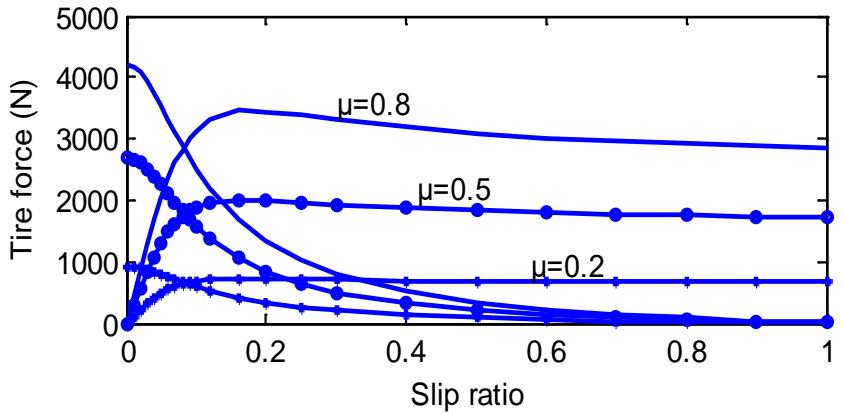

Figure 3 The Relationship between the tire force and the slip ratios $\left(F_{z}=5000 N, \alpha=5^{\circ}\right)$

The dynamic characteristic curve of the drive motors is shown in Figure 4.

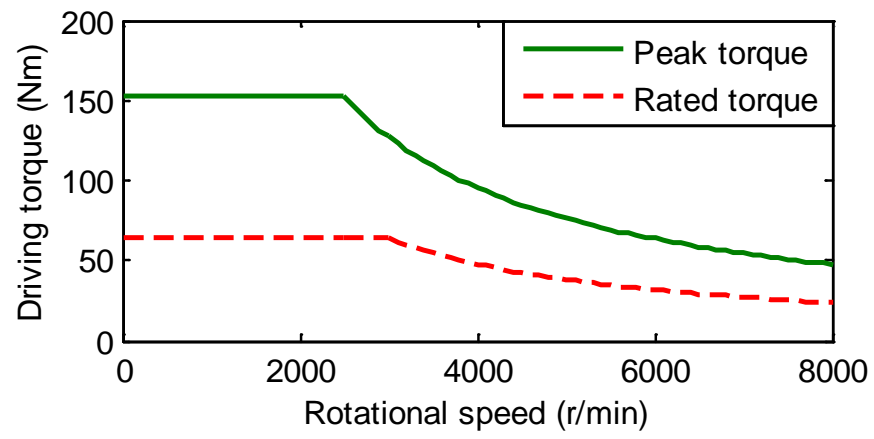

Figure 4 Dynamic characteristic curves

The pressure variation curve in the working process of the braking system is shown in Figure 5.

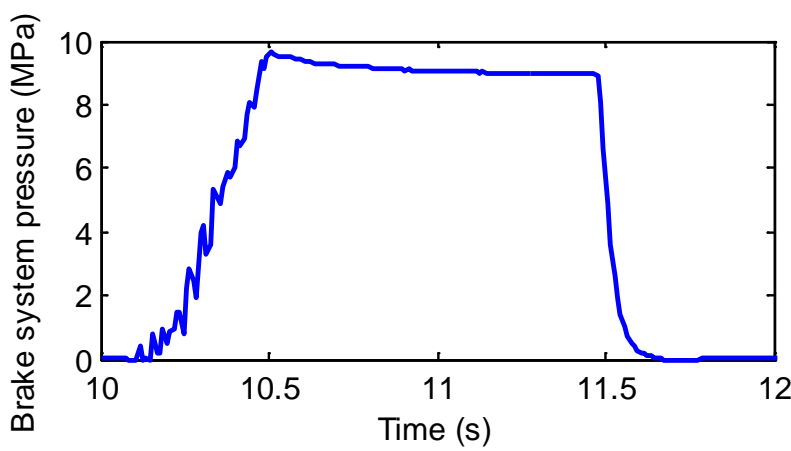

Figure 5 Brake system pressure variation curve 


\section{Transient instability mechanism}

Suppose the vehicle is full throttle accelerating without steering and the left drive system fails suddenly at the speed of $100 \mathrm{~km} / \mathrm{h}$, the subsequent vehicle movement and the change process of the corresponding state parameters are shown in figure 6, where the control effect of adjusting the torque of the normal working motor to 0 (named interception) within different delay time $t_{d}$ also have been listed. For the clarity of the simulation results, the control modes and different delay time were represented by the curves of different colours and types, which are shown in Table 2.

Table 2 Curves representing different modes and delay time.

\begin{tabular}{|c|c|c|c|}
\hline $\begin{array}{c}\text { Without } \\
\text { interception }\end{array}$ & - & $t_{d}=0.1 \mathrm{~s}$ & --- \\
\hline$t_{d}=0.2 \mathrm{~s}$ & $\cdots \cdots \cdots \cdot \cdots$ & $t_{d}=0.5 \mathrm{~s}$ & $-\cdot-$ \\
\hline
\end{tabular}

When one of the drive systems fails suddenly, the instantaneous generated additional yaw moment makes the vehicle bending greatly from the original running direction as shown in Figure 6 . Until the additional yaw moment can be counterbalance by the following generated tire lateral force,
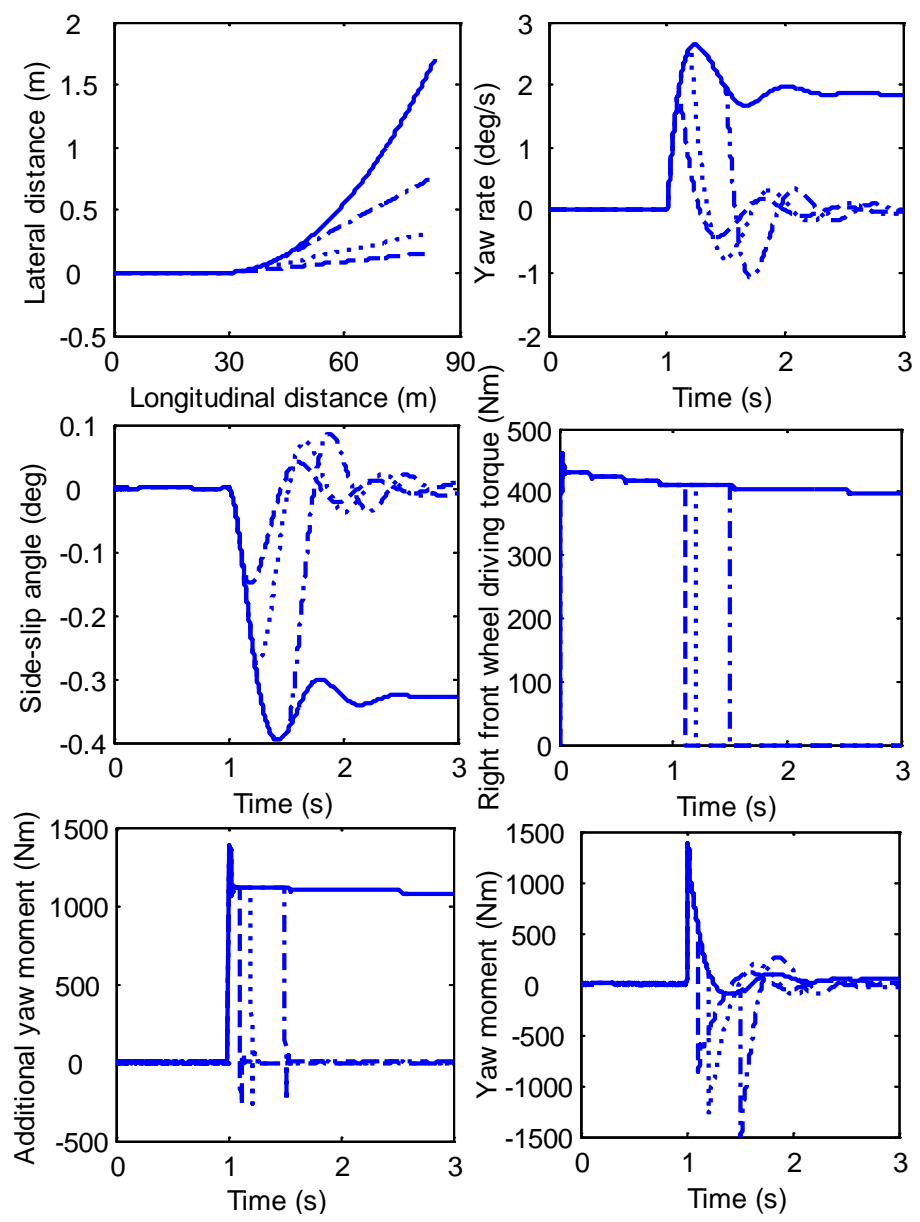

Figure 6 Vehicle movement and state parameters change process with different modes and delay time 
the yaw rate might be maintain a constant value and the vehicle is traveling along a fixed radius turn [15]. The bending of the vehicle after the motor failure has been decreased by using the torque interception method. And the stability of the vehicle is improved slightly. The additional yaw moment will disappear after adjusting the torque of the normal working motor to 0 , but it will cause the vehicle yaw moment shock, and further cause the corresponding change of the yaw rate and the side-slip angle [16]. The more the normal working motor response is delayed, the more the bending of the vehicle increases, and danger increase.

\section{Electro-hydraulic brake compensation control}

Because of the existing of delay time, the torque interception method cannot solve the instability problem caused by the failure of unilateral drive system of a two- motor drive electric vehicle fundamentally [17]. So, a more advanced control method must be used.

In the vehicle stability controller, the yaw rate $\gamma$ and the side-slip angle $\beta$ are usually used as the control variables [18]. But in the instability problem caused by the failure of unilateral drive system, the side-slip angle $\beta$ is always small and quick reduced to zero with the torque interception no matter how much the time delay, the yaw rate $\gamma$ is taken as the only control variable to adjust
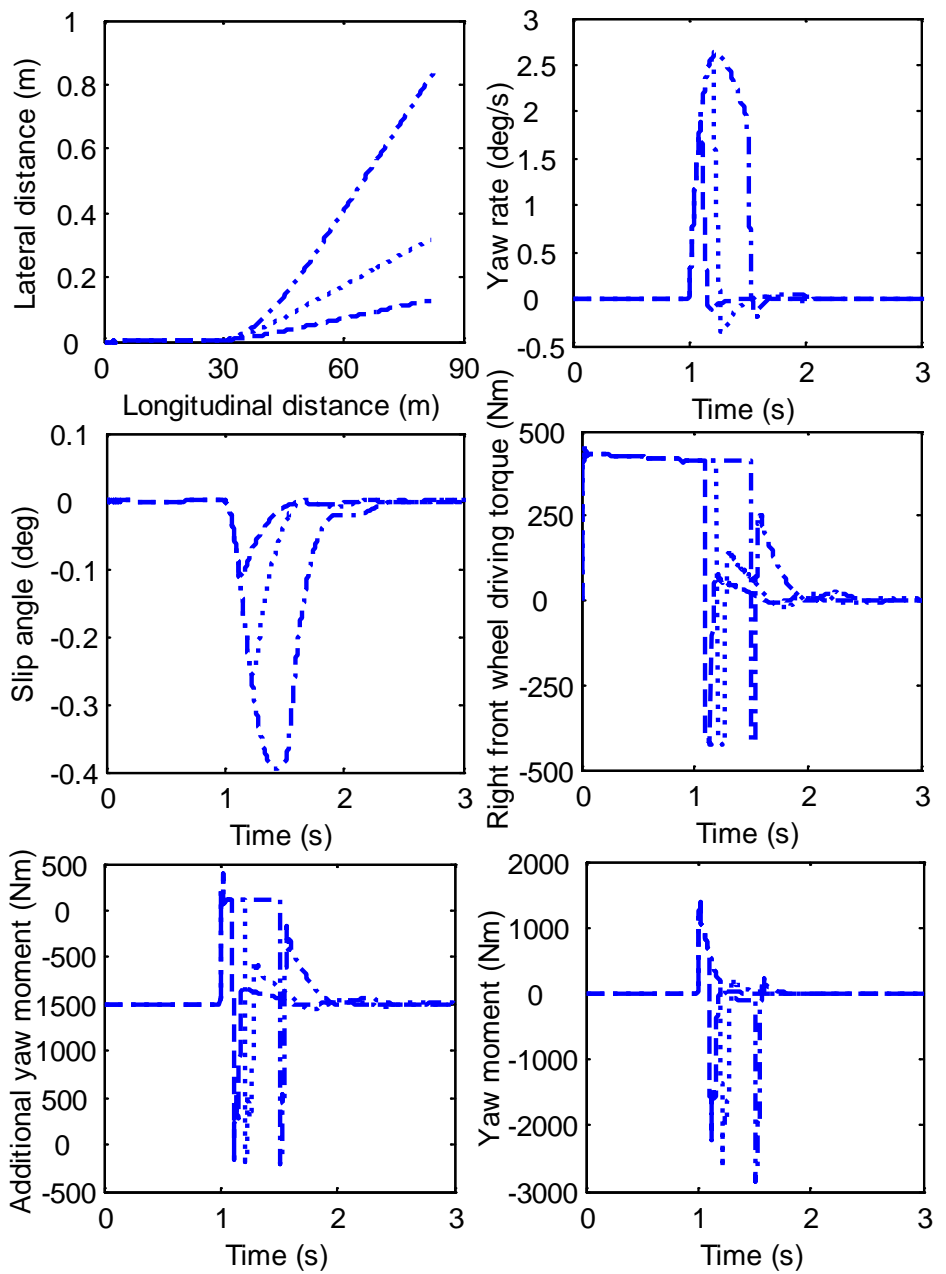

Figure 7 Control effect with different delay time 


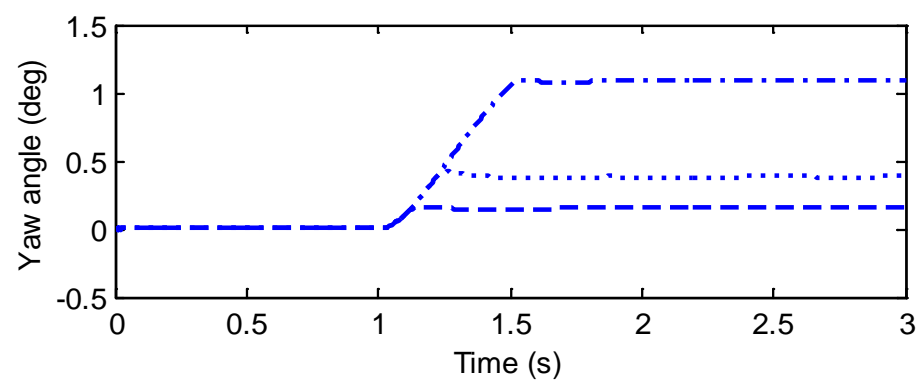

Figure 8 Yaw angle change process

the torque output from the normal working motor. The simulation results are shown in Figure 7. The stability controller based on the target yaw rate $\gamma^{*}=0$ can suppress the vehicle yaw and sideslip motion, but the motor torque adjust range is limited and the deviations still persist in the whole running process [19]. The changes of the vehicle yaw angle $\varphi$ with different delay time $t_{d}$ are shown in Figure 8. In order to drive the vehicle resume straight traveling, it is necessary to take the yaw angle $\varphi$ as another control variable in the developed control system.

The active yaw moment controller based on the electro-hydraulic composite braking in the vehicle instability critical region is developed as shown in Figure 9, where the yaw rate control is used as the inner-loop; the yaw angle control is used as the outer-loop; $\varphi^{*}$ and $\gamma^{*}$ are the target values of $\varphi$ and $\gamma ; \Delta T_{d 2}^{\prime}$ and $\Delta T_{d 2}^{\prime \prime}$ are the desired torque adjustment of the front right drive wheel; and $T_{d 21}, T_{d 22}, T_{b 21}$ and $T_{b 22}$ are the available torque adjustment output from the drive system and the brake system. The change ratios and the change scopes of the available torque adjustment values is limited by the physical characteristics of the implementation devices [20].

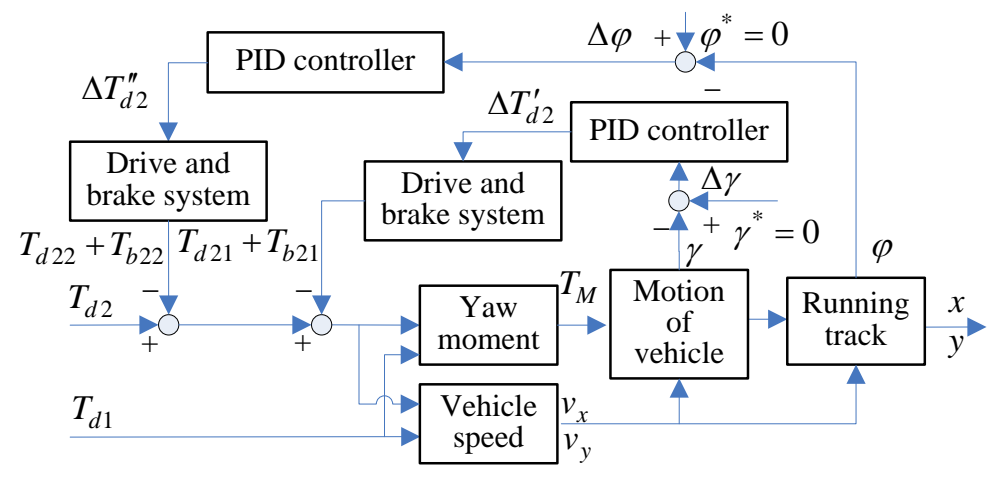

Figure 9 Brake compensation controller configuration

In order to effectively allocate the torque between the drive system and the brake system and reduce energy consumption, the brake system is started only when the torque adjustment capability of the drive system is insufficient. The control system can make full use of the respective advantages of the responsive ability of the drive motor and the abundant torque of the brake system. It is possible to maximize the stability of the vehicle [21].

\section{Control effect}

Taking the delay time $t_{d}=0.5 \mathrm{~s}$ for example, the simulation results according to the electrohydraulic composite braking control are shown in Figure 10. In order to prove the superiority of the control method, the simulation results of the control method of only adjusting the normal working 
motor torque are also listed here. For the clarity of the simulation results, different control modes were represented by the curves of different colours and types, which are shown in Table 3.

Table 3 Curves representing different modes.

\begin{tabular}{|c|c|c|c|}
\hline $\begin{array}{c}\text { Electro-hydraulic } \\
\text { composite braking } \\
\text { control }\end{array}$ & - & $\begin{array}{c}\text { motor braking } \\
\text { control }\end{array}$ & --- - \\
\hline
\end{tabular}
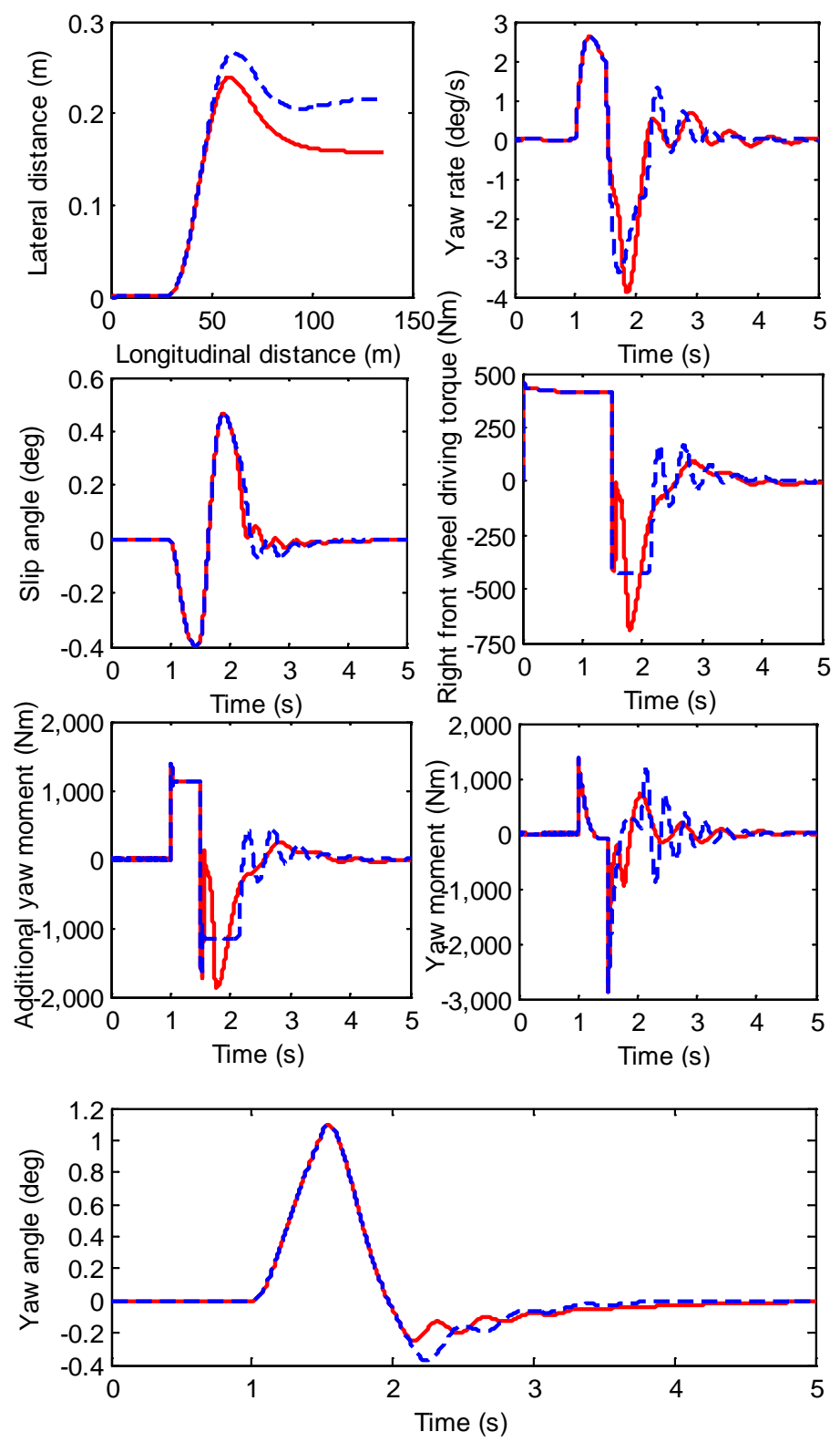

Figure 10 Control effect of different methods

The electro-hydraulic composite braking control can compensate the braking torque requirement and adjusting the variation range of the motor braking control, so the vehicle lateral distance and the variation degree of the yaw motion at the latter time of the control simulation process can be reduced. The vehicle goes back to straight traveling with a little left deflection and the stability is improved obviously. 


\section{Conclusions}

(1) When one of the drive systems of a front wheels in-wheel motors drive electric vehicle fails suddenly, the instantaneous generated additional yaw moment will make the vehicle bending greatly from the original running direction. The bending might be decreased by using the torque interception method, but the failure detection and the control system response will delay a moment, the more the normal working motor response is delayed, the more the bending of the vehicle increases, and danger increase.

(2) Adopting the electronic stability control based on the target yaw rate $\gamma^{*}=0$ can suppress the vehicle yaw and side-slip motion, but the motor torque adjust range is limited and the deviations still persist in the whole running process.

(3) Adopting the proposed electro-hydraulic composite braking control based on the target yaw rate $\gamma^{*}=0$ and the target yaw angle $\varphi^{*}=0$ can take the initiative to coordinate the torque coupling characteristics between the in-wheel motors and the brake system, which makes the vehicle back to straight traveling with a little left deflection. Therefore, the braking torque requirement is compensated and the variation range of the motor braking control is adjusted, which can improve the vehicle stability significantly.

\section{Acknowledgements}

This work was supported by the National Natural Science Foundation of China (Grant No: 51405259).

\section{References}

[1] Murata, S. (2012). Innovation by in-wheel-motor drive unit. Vehicle System Dynamics, 50(6), 807-830.

[2] Li, L., Li, X., Wang, X., Song, J., He, K., and Li, C. (2016) Analysis of downshift's improvement to energy efficiency of an electric vehicle during regenerative braking. Applied Energy, 99(8), 1-16.

[3] Du, Y. C., Qin, C. A., You, S. X., and Xia, H. C. (2017) Efficient coordinated control of regenerative braking with pneumatic anti-lock braking for hybrid electric vehicle. Science China Technological Sciences, 60(3), 1-13.

[4] Mutoh, N., and Nakano, Y. (2011) Dynamics of front-and-rear-wheel-independent-drive-type electric vehicles at the time of failure. IEEE Transactions on Industrial Electronics, 59(3), 1488-1499.

[5] Liu, X., He, H., Wang, X., and Xiong, R. (2013) Study on the Torque Allocation Strategy of the Distributed Driving Electric Vehicles Running in Straight Line with a Single Failure Motor. International Conference on Control Engineering and Communication Technology. IEEE, 378-381

[6] Wang, R., Zhang, H., and Wang, J. (2014) Linear parameter-varying controller design for four-wheel independently actuated electric ground vehicles with active steering systems. IEEE Transactions on Control Systems Technology, 22(4), 1281-1296.

[7] Chu, W. (2012) Rule-based traction system failure control of distributed electric drive vehicle. Journal of Mechanical Engineering, 48(10), 90.

[8] Miyazaki, H., and Ohmae, T. (2005) Driving stability for electric vehicle with independently driven two wheels in case of inverter failure. 11th European Conference on Power Electronics and Applications, Dresden, Germany, 1-9

[9] Lv, C., Zhang, J., Li, Y., and Yuan, Y. (2016) Directional-stability-aware brake blending control synthesis for over-actuated electric vehicles during straight-line deceleration. Mechatronics, 38,121-131.

[10] Hadda, W. M., and Kapila, V. (1996) Antiwindup controllers for systems with input nonlinearities. Journal of Guidance Control \& Dynamics, 19(6), 1387-1390. 
[11] Zhang, L., Li, L., Lin, C., Wang, C., Qi, B., and Song, J. (2014) Coaxial-coupling traction control for a fourwheel-independent-drive electric vehicle on a complex road. Proceedings of the Institution of Mechanical Engineers Part D Journal of Automobile Engineering, 228(12), 1398-1414.

[12] Kang, M., Li, L., Li, H., and Han, J. S. Z. (2012) Coordinated vehicle traction control based on engine torque and brake pressure under complicated road conditions. Vehicle System Dynamics, 50(9), 1-22.

[13] Tavoosi, V., Kazemi, R., and Oveisi, A. (2014) Nonlinear adaptive optimal control for vehicle handling improvement through steer-by-wire system. Journal of Central South University, 21(1), 100-112.

[14] Zou, T., Xiong, L., Yang, P., and Jin, C. (2015) A control allocation strategy for electric vehicles with inwheel motors and hydraulic brake system. SAE Technical Papers, 2015-01-1600.

[15] Ćirović, V., Aleksendrić, D., and Smiljanić, D. (2013) Longitudinal wheel slip control using dynamic neural networks. Mechatronics, 23(1), 135-146.

[16] Zhuoping, Y. U., Bo, L., Lu, X., Yuan, F., and Shi, F. (2016) Direct yaw moment control for distributed drive electric vehicle handling performance improvement. Chinese Journal of Mechanical Engineering, 29(3), 486-497.

[17] Liu, Y., and Sun, Z. (2015) Optimal regenerative braking control for 4wd electric vehicles with decoupled electro-hydraulic brake system. SAE Technical Papers, 2015-01-1117.

[18] Han, Y., Luo, Y., Li, K., and Chen, L. (2015) Electro-hydraulic brake control method for hybrid electric vehicle during process of downhill assist control. Transactions of the Chinese Society of Agricultural Engineering, 31(8), 112-118.

[19] Todeschini, F., Formentin, S., Panzani, G., Corno, M., Savaresi, S. M., and Zaccarian, L. (2016) Nonlinear pressure control for bbw systems via dead-zone and antiwindup compensation. IEEE Transactions on Control Systems Technology, 24(4), 1419-1431.

[20] Wang, B., Huang, X., Wang, J., and Guo, X. (2014) A robust wheel slip control design for in-wheel-motordriven electric vehicles with hydraulic and regenerative braking systems. Proceedings of the American Control Conference, 3225-3230.

[21] Savitski, D., Shyrokau, B., and Ivanov, V. (2016) Base-brake functions of electric vehicle: disturbance compensation in decoupled brake system. International Journal of Vehicle Design, 70(1), 69-97. 